\title{
Analysis of the Effect of the Intermediate Filter between Two Succes Hydraulic Structures on the Uplift Pressures
}

mohamed salem

\begin{abstract}
Abstract A study is presented on the seepage flow occurring through homogeneous soil beneath two structures in series separated by an intermediate filter with concrete blocks founded on two pervious layers. The lower layer is of very high permeability than the upper one. The objective of this study is to determine the effect of relative filter length, length of the filter/length of upstream floor, provided with concrete blocks, on the seepage characteristics (uplift pressures under the two floors and exit gradient downstream each structure). It's found that the increase in the relative filter length causes a negligible effect on the relative uplifl; pressures under the upstream floor, a decrease in the relative uplift pressures under the downstream floor, and a decrease in the exit gradient downstream the downstream structure. It's reconomended to use a filter length of the same length of the upstream floor. The concrete blocks are arranged with $20 \%$ perforated area and the block depth is $25 \%$ of upstream floor depth
\end{abstract}

